\title{
SIMULATING MOORED AND PASSING SHIP INTERACTION FOR HARBOUR AND NAVIGATION CHANNEL DESIGN
}

\author{
John Spencer, HR Wallingford, jmas@hrwallingford.co.uk \\ Mark McBride, HR Wallingford, mmcb@hrwallingford.co.uk \\ David Shennan, formerly Harwich Haven Authority
}

\begin{abstract}
Introduction
The passage of a moving ship can disturb other vessels moored nearby, particularly in a confined channel (HRS 1971, Remery 1974, Spencer 1993). The forward motion of the moving vessel generates a pressure field in the water surrounding it, which can excite movement of any moored ships in the vicinity. In extreme instances the induced movement results in damage to mooring equipment, although the more usual problem is that the movement is large enough to disrupt cargo handling.
\end{abstract}

In some circumstances, the disruption can be reduced to an acceptable level by paying attention to the vessels' moorings, such as using more, or tauter lines, and better line tending. In other cases, limits are required on passing ship speeds and/or their proximity. The problem is then to identify and set the limits appropriately.

Such limits can sometimes be set empirically, being determined by experience of similar sites and ships types and sizes, but this is not always possible. For example, it may be a new berth site, or a new, significantly different type of ship may be involved, or there may be a wish to check empirically set limits and verify that they are optimal. In these cases, either physical or computational modelling may be used to provide an analysis of the behaviour of a ship at a berth.

\section{Method}

HR Wallingford has a considerable background in physical modelling of moored ships in harbours, including examining passing ship problems (HRS, 1971), and physical modelling is still routinely used where appropriate.

This paper is, however, concerned with development and the use of computational models, which combine accuracy with economy and have become increasingly reliable in recent years.

The forces acting on the moored ship induced by the passing vessel are obtained by modelling the water flows around the two vessels. The model includes the bathymetry in the berth vicinity, and thus any restrictions on flow due to narrowness in the channel. Modelling the water flows gives the pressure field around the two ships, and the action of this pressure on the moored ship hull is calculated to give resultant forces and moments. Calculations are repeated for successive positions of the moving ship as it passes, resulting in a time series of forcing.

The forcing time series is then taken as input to a second computer model (Spencer 1988), which also incorporates the mooring and inertial characteristics of the moored ship to compute vessel movements. The motions of the moored ship, and the forces in mooring lines and fenders resulting from the forcing are output in time series form.

Typically, in the analysis of test results, the extremes of the moored vessel movement and mooring forces are compared against recognised operational criteria. These include, as examples, the achievable movement envelope of a loading arm at an oil or LNG berth, or safe operational threshold for a the crane at a container berth, and limiting loads on winches, mooring lines and fenders. Running simulations to cover the range of passing ship conditions (such as different passing ship types, speeds and separation distances), and correlating the results from different tests, the operational ranges of acceptable passing ship conditions can be identified (Figure 1).

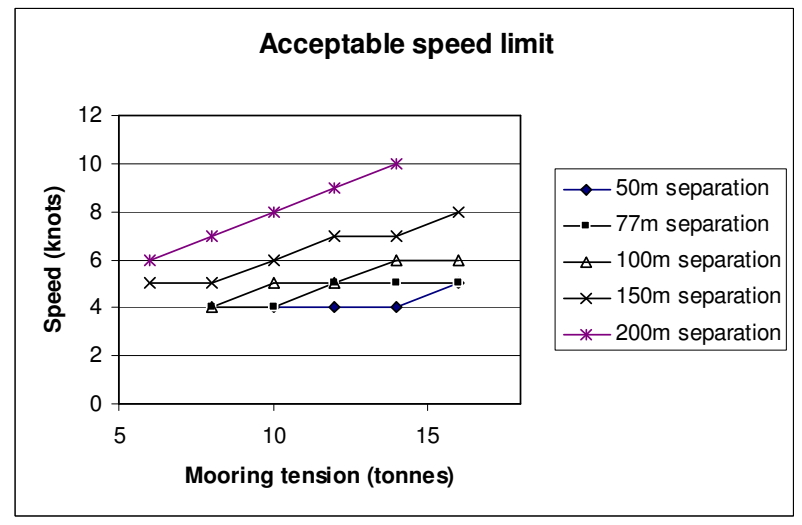

Figure 1: Operational passing speed ranges

At an existing berth, the results can be applied to set appropriate speed and proximity limits for passing ships. They can be used similarly for a new-design berth, and also provide guidance to the clearances required between berths and navigation channels.

\section{Results}

The practical application of the models in a number of case studies is demonstrated, in which computational modelling is used for simulating LNG carriers, tankers and container ships at coastal berths. Examples show the induced forces acting on a moored vessel as another ship passes, and the resulting movement of the vessel at its berth. The implications of these motions and the appropriate measures, particularly limits on passing vessel speed and proximity, required to prevent unacceptable disruption of port operations is considered. The effects of these on channel design and on port / channel configurations is also discussed. Model outputs are compared for accuracy with real world observations where available.

\section{Acknowledgements}

The authors would like to acknowledge the assistance of the Harwich Haven Authority in the preparation of this paper.

\section{References}

HRS 1971 'Effect of passing vessels on a moored ship' HRS Report EX 566, July 1971.

Remery GFM 1974 'Mooring forces induced by passing ships' Offshore Technology Conference, Paper no. 2066, Vol 2. 1974

Spencer JMA, McBride MW, Beresford PJ and Goldberg DG 1993 'Modelling the effects of passing ships' Conference on Computer Applications in Coastal and Offshore Engineering. Kuala Lumpur, Malaysia, June 1993.

Spencer JMA 1988 'Mathematical simulations of a ship moored in waves and of the effects of a passing vessel on a moored ship' HRW Report SR 145. 1988 